\title{
KAFKA: UM EsCRITOR ÀS VOLTAS COM O ESCLARECIMENTO
}

\author{
Patrícia da Silva Santos ${ }^{1}$
}

\begin{abstract}
Resumo
Com o intuito de verificar algumas das formas de como a História está presente na literatura, este artigo analisa o conto "Posêidon" de Franz Kafka e tece algumas considerações a respeito da presença do registro alegórico neste escritor.

Palavras-chave: Literatura. História. Franz Kafka.
\end{abstract}

\begin{abstract}
With intention to verify some of the forms of as History is present in literature, this article analyzes the short story "Posêidon" of Franz Kafka and offers some considerations regarding the presence of the allegoric register in this writer.

Key word: Literature. History. Franz Kafka.
\end{abstract}

$\mathrm{K}$

afka sempre esteve às voltas com o mundo do trabalho. Suas narrativas retomam a questão da profissão com freqüência. Artista, caixeiro viajante, médico, advogado, bancário, timoneiro, agrimensor; enfim, um arsenal de exemplos muito diversificados. Mas antes de taxativamente afirmar, como Günter Anders (1993), que em Kafka o homem ésua profissão ${ }^{2}$, gostaria apenas de seguir a pista do mundo do trabalho para tecer algumas considerações sobre uma narrativa específica do escritor tcheco: "Posêidon".

Sendo verdade que nenhum texto literário seja capaz de fugir do paradoxo entre a subjetividade do escritor e a objetividade da realidade que o cerca; podemos afirmar que em Kafka tal paradoxo chega ao extremo, basta observar a quantidade de correntes teóricas que retomam o escritor: marxismo, socialismo, existencialismo, psicanálise, teologia. 0 presente texto não tem a pretensão de se filiar a nenhuma corrente. As considerações que

\footnotetext{
${ }^{1}$ Mestranda em Sociologia. Universidade Estadual de São Paulo - USP. Email: patricia215@ig.com.br.

2 "Se o homem não é nada a não ser sua "profissão", se sua existência se esgota no papel em que ele é entendido, então ele mesmo não é nada, nada realmente, mas sim, de certo modo, apenas a duplicata da certidão que corre em seu nome." (ANDERS, 1993, p. 59).
} 
se seguem não se apóiam em ideologias pré-estabelecidas; antes procuram ler na narrativa 0 tecido da historicidade à qual ela pertence.

Em Posêidon Kafka visita a mitologia grega com um olhar muito peculiar. Ao invés de enaltecer o mundo mítico, o escritor denota a sua própria pertinência ao mundo do esclarecimento (Aufklärung). Neste sentido, o grande deus dos oceanos é observado em sentido burocrático e tem sua ocupação classificada como administração (Verwaltung). É para o mundo do trabalho tal qual conhecemos na sociedade moderna que Kafka traz Posêidon. De modo que a narrativa inicia com a seguinte frase: "Posêidon estava sentado à sua escrivaninha de trabalho e fazia contas". (Poseidon saß an seinem Arbeitstisch und recbnete).

0 Posêidon de Kafka pertence à classe de qualquer administrador moderno que conhecemos. A narrativa dá-lhe um caráter de grande responsabilidade afirmando que o deus dos oceanos refazia todas as contas que os seus auxiliares faziam.

Mas a hipótese que proponho não se atém apenas à crítica ao mundo do trabalho e suas características de eficiência, produtividade, que está indubitavelmente presente na narrativa. Para além dessa crítica, a característica que quero acentuar no Posêidon de Kafka é a da vitória do desencantamento (Entzauberung) sobre o mundo mítico. 0 fracasso do esclarecimento (no sentido de ADORNO; HORKHEIMER, 1985) acompanha a narrativa ao fazer do deus dos mares um administrador frustrado, preso às profundezas dos oceanos, conforme observamos no seguinte trecho:

0 que mais o irritava - e essa era a causa principal de sua insatisfação com o cargo - era escutar as imagens que faziam dele como, por exemplo, ele dirigindo sem parar sobre as ondas com o tridente. Enquanto isso, Posêidon estava sentado nas profundezas dos mares do mundo, fazendo contas ininterruptamente; de vez em quando uma viagem para se encontrar com Júpiter era a única quebra da monotonia - viagem, por sinal, de que na maioria das vezes voltava furioso.

Am meisten ärgerte er sich — und dies verursachte hauptsächlich seine Unzufriedenheit mit dem Amt - wenn er von den Vorstellungen börte, die man sich von ibm machte, wie er etwa immerfort mit dem Dreizack durch die Fluten kutschiere. Unterdessen saß er bier in der Tiefe des Weltmeeres und rechnete ununterbrochen, bie und da eine Reise zu Jupiter war die einzige Unterbrechung der Eintönigkeit, eine Reise übrigens, von der er meistens wütend zurückkehrte.

Kafka descaracteriza o estereótipo sobre o deus dos oceanos quebrando, dessa forma, com sua identidade clássica e substituindo-a pela identidade do mundo do trabalho. Ao

${ }^{3}$ Utilizo aqui a tradução de Modesto Carone presente em Kafka (2002). 
conduzir a narrativa desta forma, Kafka está reduzindo a distância estética entre leitor e narrador, tal qual afirma Adorno (2003, p. 61) em "Aposição do narrador": "Por meio de choques ele [Kafka] destrói no leitor a tranqüilidade contemplativa diante da coisa lida". Deste modo, não é que Kafka descreva a nossa sociedade do trabalho, antes ele conduz o leitor no paradoxo de uma narrativa mítica endossada por uma das categorias fundamentais do capitalismo: 0 trabalho.

Para retomar a proposta de ler a historicidade presente na narrativa, é interessante retomar o conceito de alegoria. Ficando apenas na distinção de Walter Benjamin (1984) verificamos que a alegoria reabilita a temporalidade e a historicidade em oposição ao ideal de eternidade que o símbolo encarna. Remeto Kafka ao registro alegórico para afirmar que o escritor quebra com o sentido da significação presente no período clássico ao qual pertence Posêidon. Deste modo, a "violência" da morte da narração (para a qual apontam diversos teóricos tais como Adorno (2003, p. 61) Benjamin e Paul Ricoeur (1995) só pode ser superada por formas de narrar necessariamente novas. Nada melhor do que o diagnóstico de Benjamin (1993) da presença em Kafka de uma "tradição que ficou doente" para ilustrar esta concepção de literatura no período moderno. Como afirma Gagnebin (1994,p. 19):

Kafka não teria tentado curar essa doença, mas, numa espécie de obstinação serena, tê-la-ia levado até seu fim, desistindo do modelo habitual que dá por tarefa à literatura a expressão de uma verdade exterior e fundadora.

Ao invés de apegar-se à tradição doente, numa espécie de melancolia, o autor tcheco é especificamente moderno justamente porque releva ao extremo esta condição da tradição que ficou delegada ao esquecimento.

Voltando à narrativa "Posêidon", a característica que procuro destacaré a seguinte: Kafka não critica 0 trabalho em si simplesmente, ele denota 0 quanto as categorias anteriores de significação (no caso específico, os deuses da mitologia grega), perdem 0 seu potencial revelador diante da reificação do mundo contemporâneo.

É interessante notar que Kafka nos revela o trabalho do ponto de vista do sujeito que o exerce. Não é por acaso que o sujeito da narrativa "Posêidon" seja um deus da mitologia grega. A perspectiva paradoxal faz parte da literatura kafkiana: ser caixeiro viajante ou uma barata (A Metamorfose); trabalhar como os outros ratos da comunidade ou cantar (Josefina, a cantora ou o povo dos ratos); ser o agrimensor ou apenas estrangeiro (0 Castelo); entre outros exemplos. É o indivíduo, de sua posição singular, quem ocupa o lugar de destaque da literatura kafkiana. Posêidon é deus, mas é também "escravo" desta condição. Enquanto administrador dos mares, deve zelar pela exatidão da sua 
administração (que se dá em números!). No entanto, a individualidade bem definida que a função lhe confere também serve para limitar a sua liberdade. De modo que Posêidon espera o fim do mundo para ter um instante de liberdade:

Costumava dizer que ia esperar o fim do mundo, aí então se produziria com certeza um segundo de tranqüilidade, no qual ele, bem próximo ao fim, depois de revisar o último cálculo, poderia ainda dar, rapidamente, um pequeno giro por tudo.

Er pflegte zu sagen, er warte damit bis zum Weltuntergang, dann werde sich wohl noch ein stiller Augenblick ergeben, wo er knapp vor dem Ende nach Durchsicht der letzten Rechnung noch schnell eine kleine Rundfahrt werde machen können.

Kafka soube ler de maneira extraordinariamente bem o espírito contraditório do nosso tempo. É isto que confere o poder de historicidade das suas narrativas.

\section{REFERÊNCIAS}

ADORNO, Theodor. Notas de literatura I. São Paulo: Ed 34, 2003.

ADORNO, Theodor; HORKHEIMER, Max. Dialética do esclarecimento. Rio de Janeiro: Jorge Zahar Editor, 1985.

ANDERS, Günter. Kafka: pró e contra. São Paulo: Perspectiva, 1993.

BENJAMIN, W. Experiência e pobreza. In: Documentos de Cultura, Documentos de Barbárie. Trad. Celeste H. M. Ribeiro de Souza et al. São Paulo: Cultrix, 1986.

0 Narrador: considerações sobre a Obra de Nikolai Leskov. In: e técnica, arte e politica. São Paulo: Brasiliense, 1994. Magia . Carta à Gerschom Scholem (12.06.38). trad. Modesto Carone. Novos Estudos CEBRAP, n. 35, p. 100-106, mar. 1993.

Origem do Drama Barroco Alemão. Tradução Sérgio Paulo Rouanet. São Paulo: Brasiliense, 1984.

GAGNEBIN, Jeanne-Marie. História e narração em W. Benjamin. São Paulo: Perspectiva, 1994.

KAFKA, Franz. Narrativas do espólio. São Paulo: Companhia das Letras, 2002.

RICOEUR, Paul. Tempo e narrativa. Tradução Marina Appenzeller. Campinas: Papirus, $1995.3 \mathrm{v}$. 